\title{
Survival/success of dental implants with acid-etched surfaces: Retrospective evaluation of 10 years
}

\author{
Lélis Gustavo Nicoli, Guilherme José Pimentel Lopes de Oliveira, Paulo Fermino da Costa Neto, Beatriz Maria \\ Valério Lopes, Cláudio Marcantonio, Daniela Leal Zandim-Barcellos, Elcio Marcantonio Jr
}
Department of Diagnosis and Surgery, School of Dentistry at Araraquara, UNESP - Univ Estadual Paulista, Araraquara, Brazil.

\section{Background}

Despite the great advantages offered by the increased contact area of bone and acid-etched implant surface, under conditions of periimplant bone loss, the presence of a rough surface appears to favor biofilm accumulation and thereby promote the development of periimplantitis. The evaluation of these acid-etched implants after long periods of use is needed to determine the impact of their surface on the survival rate and success of these implants.

\section{Aim}

The present study aimed to evaluate the success rate and survival of implants with surfaces treated with double acid attack that had been used for a period of 8-10 years.

\section{Methods and Materials}

This retrospective observational study was performed in patients who underwent oral rehabilitation treatment using dental implants after a period of 8 to 10 years of use. The following clinical parameters were evaluated: visible plaque index (VPI), gingival bleeding index (GBI), probing depth (PD), bleeding on probing (BOP), clinical attachment level (CAL), presence of suppuration, presence and amount of keratinized tissue in implants, and distance between the implant platform and the bone-implant contact by periapical radiography. To determine the success of the implants, the following criteria were considered: absence of peri-implant infection, lack of mobility, absence of persistent pain or dysesthesia and absence of continuous radiolucency around the implant . Peri-implantitis was defined as implants that presented PD $\geq 5 \mathrm{~mm}$, with the presence of BOP and/or suppuration, and with radiographic confirmation of bone loss.

\section{Clinical and Radiographic Analysis}

- Anamnesis

- Visible plaque index (VPI)

- Gingival bleeding index (GBI)

Probing depth (PD)

- Bleeding on probing (BOP)

- Clinical attachment level (CAL)

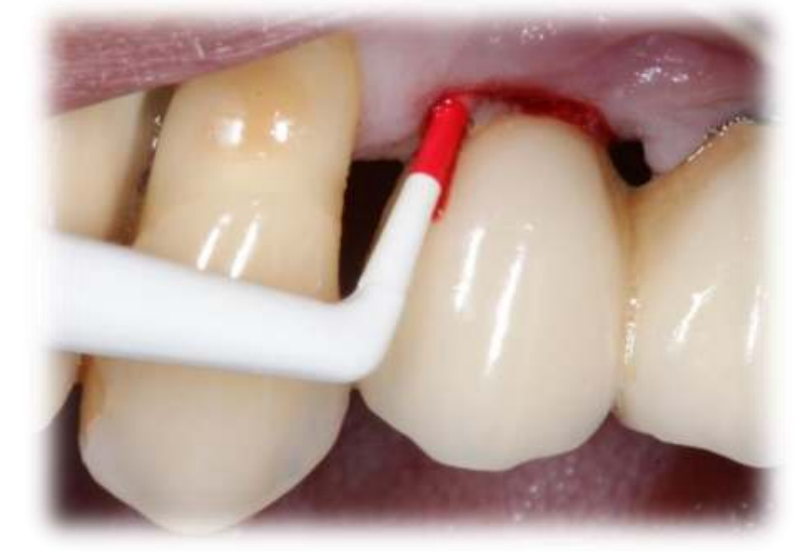

\section{Criteria for Implant Success Evaluation}

Absence of peri-implant infection

Lack of mobility

Absence of persistent pain or dysesthesia

Absence of continuous radiolucency around the implant

\section{Classification of implants}

Failed

Lost implant, removed, with mobility or fracture

Surviving

Implants that don't fit in the failure or sucess criteria

Successful
Implants in function that fit in the criteria of sucess

\section{Statistical Analysis}

The results were analyzed using descriptive statistical analysis of the obtained data. The data were allocated in relation to the sampling units as individuals and implants. The analysis was performed using measures of the central tendency, including the means and medians, and the standard deviation was used as a dispersion parameter measurement. The GraphPad Prism software 6 (San Diego, CA, USA) was used for the descriptive statistical analysis.

\section{Results}

Table 1. Characteristics of individuals in relation to the incidence of peri-implantitis

\begin{tabular}{|l|l|l|l|}
\hline Characteristics & $\mathbf{n}$ & $\begin{array}{c}\text { Peri-implantitis } \\
(\%)\end{array}$ & $\begin{array}{c}\text { Healthy } \\
(\%)\end{array}$ \\
\hline $\begin{array}{l}\text { Number of } \\
\text { patients }\end{array}$ & 44 & $11(25)$ & $33(75)$ \\
\hline Female & 26 & $07(35)$ & $19(65)$ \\
\hline Male & 18 & $04(13.3)$ & $14(86.7)$ \\
\hline Smoker & 03 & $00(00)$ & $03(100)$ \\
\hline Former smoker & 10 & $04(40)$ & $06(60)$ \\
\hline Non smoker & 31 & $07(22.6)$ & $24(77.4)$ \\
\hline Diabetes & 07 & $02(28.6)$ & $05(71.4)$ \\
\hline Osteoporosis & 07 & $03(42.8)$ & $04(57.2)$ \\
\hline $\begin{array}{l}\text { Cardiovascular } \\
\text { disease }\end{array}$ & 04 & $01(25)$ & $03(75)$ \\
\hline Hypothyroidism & 04 & $01(25)$ & $03(75)$ \\
\hline $\begin{array}{l}\text { Chronic } \\
\text { Periodontitis }\end{array}$ & 20 & $03(15)$ & $17(85)$ \\
\hline
\end{tabular}

Table 2. Classification of the implants

\begin{tabular}{|l|c|c|}
\hline Classification & N & $\%$ \\
\hline Failure & 5 & 2.7 \\
\hline Surviving & 178 & 97.3 \\
\hline Success & 155 & 84.7 \\
\hline
\end{tabular}

\section{Conclusions}

Implants with acid-etched surfaces showed high survival and success rates after a period of 8 to 10 years of use. This result demonstrates that implants with acid-etched surfaces were effective and predictable for obtaining good clinical outcomes that were maintained for a long period of observation.

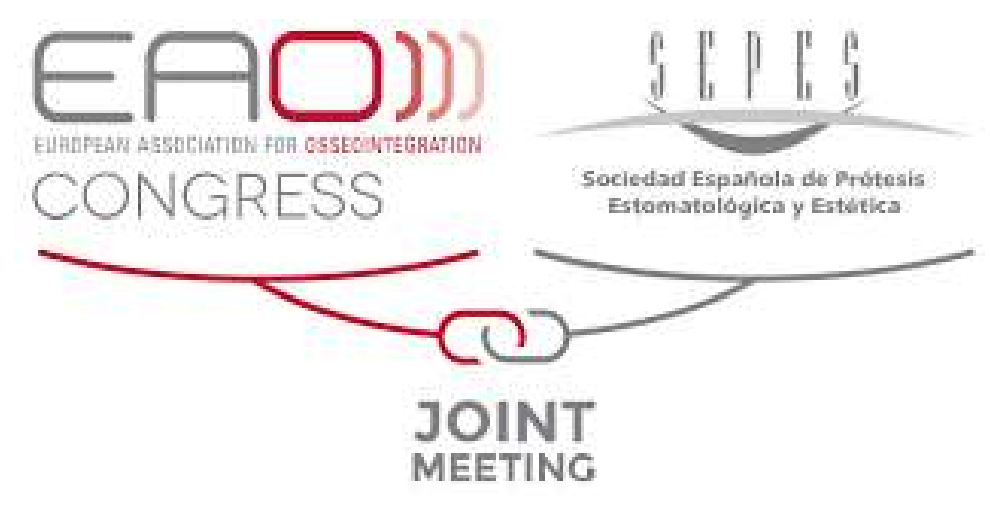

